Boise State University

ScholarWorks

$1-1-2004$

"Moving On," Men and the Changing Character of Interwar Working-Class Neighborhoods: From the Files of the Manchester and Liverpool City Police

Joanne Klein

Boise State University 


\section{"MOVING ON," MEN AND THE CHANGING CHARACTER OF INTERWAR WORKING-CLASS NEIGHBORHOODS: FROM THE FILES OF THE MANCHESTER AND LIVERPOOL CITY POLICE}

\section{By Joanne Klein}

Boise State University

The history of English working-class culture has relied on oral interviews, court records, newspapers and middle-class charity records since ordinary workingclass people rarely left behind written accounts of their lives. Elizabeth Roberts, Ellen Ross, and Melanie Tebbutt have used such sources in their path-breaking work on the lives of working-class women ${ }^{1}$ and Andrew Davies has in his impressive study of the leisure of working-class men and women. ${ }^{2}$ An untapped written record of working-class life, the investigations of complaints made to the Manchester and Liverpool City Police forces in the 1920s and 1930s by working-class people about their police neighbors, expands and refines the patterns they found. Even though these records are hampered by missing interviews, contradictory testimony of neighbors, and policemen doing the interviews not always comprehending the dynamics of neighborhood quarrels, the letters, interviews and petitions from personnel files and disciplinary report books bring to life vivid incidents in working-class neighborhoods. The police evidence is by nature negative but nevertheless indicates who was involved in neighborhood disputes, what expectations people had about their neighbors, and how they tried to enforce neighborhood standards.

From this evidence a more complex picture of working-class neighborhoods between the two world wars emerges. While women remained the main presence due to their responsibility for domestic life, men were also present in neighborhoods, defending their wives and families as well as threats to their masculinity. This supports and builds on Catherine Hall and Joanna Bourke's conclusions that men were becoming more involved at home after the First World War. ${ }^{3}$ With more families moving in and out, unlike more stable prewar neighborhoods, both women and men tried to secure congenial neighbors, with strategies and tactics designed to support good neighbors and pressure unsatisfactory neighbors to conform or move out. The increasing involvement of men made these struggles more acrimonious than they might have been with only women present. Generally speaking, neighbors desiring quiet and privacy had less success in imposing their will on more sociable people and were more likely to be forced to move. Regardless of improvements in standards of living, attempts to impose a more reserved idea of neighborliness experienced difficulties in displacing the existing, more outgoing culture when the two ideas were in conflict. When Constable Jones got tired of Mrs. Woods' habit of asking him where he was going, and told her to "Get in you old hag. What the h- has it got to do with you where I am going?", he was the one compelled to move elsewhere after Mr. Woods protested such rudeness to his wife. ${ }^{4}$ While conflicts between competing families or factions might be centered on privacy or noise on the surface, underlying problems 
often involved perceptions of subtle differences in status and respectability in jeopardy. A shift in the dynamics in neighborhoods was clear. Unlike the more stable and homogeneous streets that Ross found in pre-war London, post-war neighborhoods were slowly losing long-term residents and becoming more diverse and variable; men were spending more time with their families and were more entangled in neighborhood interactions, resulting in disputes becoming more full-blown.

In many ways, the basic picture of working-class neighborhood life remained much the same as that which existed before the First World War. In crowded conditions, neighbors recognized the necessity for similar standards of conduct along each street or block. A comfortable life required a common awareness of space, including noise and boundaries. Streets could be noisy, quiet, tidy or casual. Neighbors could be gossipy or keep to themselves. Children could be subdued or boisterous. Wives developed diverse survival networks to help each other from one pay period to the next. ${ }^{5}$ Each area created its own character. Then during the 1920s and 1930s, working-class families began to move more frequently due to improvements in transportation, construction of new housing, and changing job markets. The character of established streets and survival strategies evolved as families came and went. Usually this happened slowly as new families both adjusted to and modified local standards but occasionally a sharp change could throw a street into confusion. A family could be perceived as abruptly lowering the status of a street or as flaunting its superiority over existing residents, creating anxiety over respectability. If a new family was too different from a street's character, neighbors did not suffer in silence, but started campaigns of complaints, arguments, and harassment to enforce conformity. New families trying to impose their own standards on streets fought back with similar tactics. If different standards became too aggravating, efforts could be made to force families to move.

The growing number of men at home with their families added complications of masculinity to disputes that had previously been more exclusively the domain of women. Wives bickering over children became men jumping to the defense of their offspring. Disputes over common entry ways led to men yelling at neighbor's wives, whose husbands then came to their defense, resulting in public shouting matches. Men competed over allotments and defended their territory ${ }^{6}$ Neighborly conflicts could become "rooster" competitions, defined by status of jobs, productivity of gardens, motor cycles versus bicycles and other signs of importance. The majority of complaints lodged with local police were made by men rather than women though no doubt at least some husbands filed complaints at the behest of their wives. Writing a letter appealed to men's notion of taking charge, in addition to giving them an opportunity to present their actions in a positive light in contrast to the boorish behavior of their neighbors.

Neighbors trying to enforce certain standards needed to be careful in choosing their strategy. More than one pattern of behavior might be competing for dominance on a street, especially if more than one new family had moved in recently. Standards could shift, leaving older neighbors to cope with the suddenly changed character of their street. Pushing too hard for one set of standards could backfire. The investigations into complaints regarding police families indicate that those trying to establish certain standards did not inevitably succeed, be 
they police or civilian neighbors. On the one hand, even if a complaint did not lead to any charge being made against the police officer, people might consider it worthwhile to show neighbors how far they were prepared to go to enforce acceptable behavior. On the other hand, if a neighbor proved to be more popular with the street than the complainant, the latter might be the one whose behavior proved to be unacceptable. In either case, families or individuals who did not fit into the neighborhood climate either learned to compromise, perhaps hoping that new families would support their point of view, or they moved in search of a more congenial street.

Policemen were particularly susceptible to neighborhood pressures since police forces could not afford to have their men in conflict with their neighbors. Policemen were expected to uphold the image of the police force both on and off the job. When the 1919 Police Act created higher standards of pay and promotion, this expectation became even stronger at the same time that neighborhoods became less stable. Neighbors soon learned that reporting policemen to their chief constables for unseemly conduct was an effective way to force police families to change their behavior or move. ${ }^{7}$ Few complaints from neighbors appear in the records before 1919, but afterwards Manchester Chief Constable Maxwell protested that he was constantly receiving complaints from police neighbors that on investigation proved to be a result of "idle and stupid gossip." 8 Police authorities could not afford to ignore complaints, however frivolous, since "Idle and vindictive gossip and interference with the affairs of others ... cannot but bring discredit upon the whole of the Force." Even though Mr. Todd's complaint that the McLellans had been generally offensive was dismissed as unfounded, Liverpool Sergeant McLellan was advised by his superintendent that "this sort of thing was undesireable $\&$ might mean he would have to move if it did not stop." ${ }^{10}$ Neighbors took advantage of this, that even baseless complaints to police authorities could get the results they desired. Superior police officers constantly advised police families and their neighbors to be tolerant and get along with each other but the complaints continued.

For most working-class families, public displays of cleanliness had long been a tactic to indicate the respectability of families. Roberts, Tebbutt and others have explored how wives and daughters spent hours cleaning the steps and flagstones in front of their doorways, cleaning and starching curtains, and generally making sure that the public appearance of the family was a good one. ${ }^{11}$ With more husbands at home, rancor over appearances escalated as men began clashing with neighboring wives whose husbands then came to their defense. A remarkable picture is created of men fighting over housekeeping standards. For example, in a clear violation of space given working-class preoccupation with clean entryways, Mrs. Dutch habitually threw refuse and ashes out of her back door with much of it landing in front of the Pirie's back door. Even if she had kept her trash on her own side, having a neighbor who simply threw trash onto the ground rather than into a container lowered the status of the street. Her thoughtlessness undermined both her own status and that of the Piries. Finally, no doubt after clashes between the wives, Constable Pirie yelled at her. Mr. Dutch accused him of bullying his wife, and the situation degenerated into a shouting match between the husbands. ${ }^{12}$ While wives most likely got their husbands involved, the men did not distance themselves from the issue. If friction became intense 
enough, a family could be driven into moving. Mrs. Young enjoyed feeding birds but $\mathrm{Mr}$. Scott accused her of encouraging rats. In response to this nasty slur against his wife's housekeeping, Constable Young shoved Mr. Scott out of his garden gate. The neighbors apparently sided with the birds, or did not care for Mr. Scott's tactics, since it was the Scotts who moved. ${ }^{13}$ The public nature of these disputes intensified disagreements as men jockeyed for position. However, only one example of a serious physical assault exists in the records so if disputes degenerated into fist fights, no one reported it. ${ }^{14}$ Generally speaking, when neighbors with stricter standards of cleanliness and privacy came into conflict with more casual families, the stricter families had little success in getting their neighbors to adopt different habits.

In addition to cleanliness, the behavior of children indicated the standing of families. Not always having parks near by, children played in local streets and entry ways. Mothers kept on eye not only on their own but on neighbors' children, both helping and chastising them when necessary. ${ }^{15}$ Diverging definitions of proper conduct could lead to neighbors questioning each other's parenting skills. Episodes involving children could degenerate into verbal battles such as when Mrs. Lord and Constable Baker "exchanged words" after the Lord's son took a fire shovel away from Baker's son and the constable went to get it back. ${ }^{16}$ Men began taking a larger role in child rearing, and could lose status if they could not control their children. ${ }^{17}$ Fathers disciplined their children, as when Constable Corlett sent his child to apologize for throwing cabbage leaves into the Beeney garden and when Mr. Ferguson punished his son for kicking the Tinsley girl, even though she had kicked the boy first. But childish pranks and quarrels could get out of hand when fathers stepped in to protect their families. Mr. Beeney responded to the apology by yelling at Mrs. Corlett for not controlling her child while his wife yelled at the child sent to apologize. Not considering Mr. Ferguson's punishment good enough, Constable Tinsley "threatened to kick the boy from one end of the road to the other." ${ }^{.18}$ Fathers could escalate quarrels, perceiving threats to their parenting skills or to their children as challenges to their masculine standing as good fathers.

The most violent neighborly disputes involving men tended to center on gardens and allotments, a growing part of husbands' responsibilities during the interwar period. Men could perceive intrusions into their yards as a direct threat to their status in the neighborhood, often by another man. These quarrels more often led to a family moving than other disagreements since they involved more serious problems of trespassing and physical damage. Aggressions often seemed to be played out in assaulting hedges, the physical barrier dividing one man's territory from another's. To prevent the Williams children from using his yard as a shortcut, Mr. House stopped pruning his hedge. Constable Williams responded by cutting the hedge without permission and using filthy language when Mr. House objected. Williams was warned that he would have to move if he could not learn to live with the Houses so Mr. House made his point. ${ }^{19}$ $\mathrm{Mr}$. Grundy was less successful in his complaint against Constable Pritchard. A hedge dividing Mr. Grundy' yard from Pritchard's allotment had reached a height of eighteen feet and came five feet into the allotment. This both stole territory from Pritchard and reflected poorly on the appearances of the neighborhood. Mr. Grundy complained when Pritchard "mutilated" the hedge where it crossed 
onto his land, but since the hedge violated corporation regulations, Pritchard was merely advised to let Grundy know what he was doing next time. ${ }^{20}$ The growing prevalence of men investing in their gardens created a new form of territorial combat, personified by men with clippers assaulting each other's hedges.

Anxieties regarding respectability were often concealed by seemingly trivial complaints over children, gardens or noise. Complaints over noise appeared more frequently than any others, since sound could travel across boundaries more readily than the sources of most other complaints. Noisy neighbors annoyed quiet ones trying to sleep, relax or get work done and talkative neighbors upset those less tolerant of gossip or concerned to protect their privacy. Noise problems could be associated with people working different shifts. George Jackson complained that the family of Constable Boss made unnecessary noise early in the morning "poking fires" 21 while an elderly couple complained that Sergeant Charnley made too much noise late at night banging doors. ${ }^{22}$ The minor yet annoying quality of these disagreements over what constituted inappropriate noise is indicated by Mr. Peck's complaint that Constable Mutch and his wife kept banging on the wall between their homes. Mutch replied that his wife had indeed banged on the wall but only because someone in Peck's home had been playing the piano early in the morning. ${ }^{23}$ Finding an acceptable combination of sociability and quiet required patience and tolerance as families moved in and out. Competing standards struggling on one street created vexation for everyone.

Demands for quiet could be complicated by sensitivities regarding neighborhood standing. Andrew Davies has explored how tangible signs of the economic success of families heightened a sense of inadequacy among those who could not afford them. ${ }^{24}$ The novelty of radios required time for people to become accustomed to their noisy capabilities. New owners experimenting with tuners and volume controls aggravated less fortunate neighbors. The acrimony between Constable Turner and two of his neighbors over his loud wireless set became so severe that Turner began writing abusive letters to them and they responded by turning him in to his superior officers. ${ }^{25}$ Interwar status items included radios, gramophones and motorcycles which appealed to men's affinity for tinkering and other suitably male mechanical pursuits. Constable Casson was no doubt proud of his air-cooled motorcycle but a neighbor, upset by the noise, coveting the cycle or both, complained that its engine disturbed his sleep. ${ }^{26}$ Those preferring quiet perceived their noisier neighbors to be ill-behaved and in consequence lowering the status of the street, although envy of pianos and other loud luxury items was clearly a factor.

While noisy status symbols could annoy those without, neighbors constantly demanding quiet could create the impression that they were 'above' their neighbors, upsetting those feeling snubbed. Neighbors who did not mind a little noise rarely complained about quiet neighbors, but people preferring quiet could be relentless in their demands for it. Mr. Sutherland and his daughter made a practice of lodging complaints at a local police station regarding radios and noisy children. They drove one family into moving, showing the effectiveness of their tactics. When Constable Higgins moved in, Miss Sutherland threatened to report him for playing a radio at 11:00 p.m. After four months of complaints by Mr. Sutherland and letter writing by Miss Sutherland, Higgins decided to move as well. ${ }^{27}$ Nevertheless, quieter neighbors rarely enjoyed this kind of success in 
imposing their will on noisier households. Superior officers almost never charged constables in such cases but instead gave "advice about living amicably with ... neighbours. ${ }^{\text {"28 }}$ Both those preferring quiet and those preferring a more lively atmosphere got on each other's nerves, encouraging families to find streets where habits meshed with their own.

Feuds over noise could become nasty when older residents sensed that they were losing control of their neighborhoods to an influx of newcomers. A quiet neighborhood was overrun by livelier families, gregarious older residents were shunned by new residents preferring to keep to themselves, and parents with now grown-up children forgot how to tolerate noisy young families. Long-time residents could find themselves out of line with the new character of the street. Some fought back, trying to keep their neighborhoods from changing. Larch Street endured a long struggle between old and new residents over their neighborhood that came to a crisis on Guy Fawkes Day. Constable Wright allowed his three sons and other boys to build a bonfire in his front yard and set off firecrackers. When Eva Kaufman came home from work, her invalid mother complained that the firecrackers were giving her a headache. Making no effort to resolve the problem diplomatically, Miss Kaufman, a long-time resident of the street, threw a bowl of water on the fire. Mrs. Wright came out and argued with her for ruining the boys' fun. Constable Wright later explained, "Hearing an argument was taking place, I went out and saw Eva Kaufman ... She then threw the bowl at my wife. The bowl passed my wife and hit me. She then got hold of my wife and ... she picked the bowl up again and hit my wife with it." Wright came to the defense of his wife. According to Miss Kaufman, "Constable Wright ran at me and took hold of me by the throat, and dragged me along a passage ... I screamed ... I admit that I did smack the constable in his face." ${ }^{29}$ This violent encounter was the culmination of the frustration of original neighbors over losing control of the street to newer ones like the Wrights, no doubt equally irritated by older families impatient with the normal activities of children, especially on national holidays. ${ }^{30}$

Competing factions of old versus new neighbors tried to drive each other off Larch Street, the extreme result of neighbors unable to resolve their differences. In an attempt to get rid of Wright and his family, an anonymous letter from one of the older residents brought the brawl to the attention of the chief constable. The illiteracy of the letter suggests that part of the problem may have been tensions between older neighbors protective of their respectability in the face of more educated new-comers. The letter concluded, "I think it is quite time there was A stop to there [sic] carrings [sic] on he is making what was a quite [sic] Street into a very rowdy street he can leave no one alone there we have lived over 40 years in the Street never seen such carrying on untill [sic] he came Disgracefull [sic] to the Manchester police force hoping there will be something done for peace to the neighborrs [sic]." ${ }^{31}$ Soon after the investigation was underway, a petition signed by twenty men and women from eight houses on the block arrived, stating that the Wrights were quiet, respectable neighbors and begging that the family be allowed to stay on the street. Clearly, two very different views on what constituted disgraceful conduct and respectability existed. Wright's popularity may have come from his willingness to entertain neighborhood boys on patriotic occasions as well as neighbors feeling more secure with a policeman 
on the street. The petition could also have been a sign of Miss Kaufman's lack of popularity. With an invalid mother, she may have annoyed neighbors with frequent calls for quiet as well as taking out the pressures of dealing with an invalid mother on others. The anonymous letter and subsequent investigation did lead to Wright being reduced in rank and warned for discreditable conduct; however, the petition worked to the extent that his family was not required to move. The tension between people desiring quiet and those living more public lives ended in something of a stalemate. Wright had the support of many neighbors but his punishment gave satisfaction to those who preferred a calmer atmosphere.

Neighborhood tensions could be sparked by distress over respectability, such as when a family flaunted their sense of superiority over others and when a quiet family was perceived as insinuating that they were too good for their neighbors. If tensions became severe enough, neighbors took measures to force families to move elsewhere. Policemen had to live in housing approved by their forces, and the Entwistles felt that their new neighborhood was not up to their personal standards. They were determined to rid themselves of three neighbors through a campaign of escalating harassment. They "would sit at the kitchen and parlour windows and make faces at the children while they were playing" and would order away children whenever they played in the street or alley. They played their new wireless set at one and two in the morning. When Mrs. Butler got permission from Mrs. Earl to hang washing on her line, Constable Entwistle ordered her to take it down since it was blocking his light. More seriously, he tried to get the Earl's son fired from his newspaper delivery job for "giving impudence to his wife," and tried to get the Butlers evicted for having too many people in their house. But their strategy finally backfired. In what began as a prank, children hoping to cause a little trouble threw a rug belonging to Mrs. Entwistle into the back yard of Mrs. Smith. Mrs. Smith found the rug and hung it on the clothes line. Even though she saw the rug on the line, Mrs. Entwistle reported the rug as stolen rather than doing the neighborly thing and asking Mrs. Smith about it. Two police officers appeared at the Smith's house to investigate. To Mrs. Smith, who felt she had done the right thing by hanging the unknown rug where it could be seen and claimed, being accused of stealing challenged her respectability. In the face of these intolerable conditions, neighborhood husbands organized a letter-writing campaign. Mr. Smith, writing more in sorrow than in anger, described how, at the bidding of Entwistle, two officers had "in quite a bullying and offensive manner accused [his wife] of stealing a piece of carpet.... to gratify the personal spite this officer and his wife have against all the neighbours on both sides." After a thorough investigation, the police superintendent concluded that "the whole of the trouble is a domestic quarrel apparently originating from a little spite and jealousy by the neighbours towards Entwistle's wife who is rather of the superior type and never at a loss for words. Entwistle is undoubtedly guided by his wife who seems to have a domineering influence over him." The neighbors succeeded in freeing their block from this abrasive family when the constable was told to find a house in a different neighborhood and advised to reform his domestic behavior. ${ }^{32}$

Involving men in formerly predominantly female neighborhood disputes could create differences in opinion over who made a good neighbor. Women home 
most of the day could find behavior more or less aggravating than men home only after work. Husbands might disapprove of other men's actions that did not upset their wives. This could lead to competing efforts to reform or move certain families. The wives along May Drive did not like Mrs. Hall, a quiet woman who aggravated many of them with her superior ways. Mrs. Carlis was well-liked as an enthusiastic supporter of the local partiality for talking in doorways and kitchens. Equally annoyed by Mrs. Hall, she began hounding her, hitting her at least once and encouraging her child to hit the Hall child. This only increased her popularity with other wives hoping to drive out the Halls. But her strategy was frustrated by a local husband. One evening, Sergeant Carlis came home to find his wife arguing with Sergeant and Mrs. Hall over a fight between their children. He got his wife home and knocked her down, as seen by two terrified children through the window. Their father, not wanting his children to witness such scenes, wrote to the chief constable, adding that it was not the first occasion for such an outbreak. Carlis defended his behavior, arguing that his wife was lazy, dirty, in debt, and corresponding with a sailor. ${ }^{33}$ But he added, "Other neighbours take the side of my wife because she gossips freely with them whereas Mrs Hall minds her own business." While the wives wanted to keep Mrs. Carlis, a father angry at his children witnessing a violent husband considered Sergeant Carlis to be a bad neighbor. As a result of his complaint, the Carlises moved from the street. ${ }^{34}$ The wives lost a good gossip but the father had protected his children from the sight of a policeman hitting a wife he could not control.

The growing presence of men in neighborhood disputes left them open to questions regarding their masculinity if they were perceived as not controlling their wives. Many complaints against the behavior of police wives stated that they did not want the husbands to get into trouble but did want them to stop their wives' unacceptable behavior, though it is clear from investigations that many husbands had a difficult time governing wives. Constable Thompson had little influence over his wife who enjoyed antagonizing her neighbors, including accusing one wife of having bugs in her house to that woman's distress. After neighbors complained, a police inspector spoke to her about her behavior in the presence of her husband but even this authority figure had no effect. Finally, eight families, including another police family, sent a petition to the police, stating that "it would be to the very great benefit $\&$ satisfaction of all, if the family living in number 12 were removed." The police agreed and moved the Thompsons. The only complaint about Constable Thompson was "that he has no control over his wife," a fairly typical remark in cases where wives were seen as the primary source of trouble. ${ }^{35}$ In spite of men being more involved at home, they remained absent much of the time and women still dominated the domestic sphere.

The complexities of changing relationships in a working-class neighborhood are revealed by a minor children's quarrel in an entry way between Princess Road and Russell Street which precipitated a crisis combining issues of respectability, boundaries, masculinity, children, gossip and change. The roots of the crisis went back a year when two new families moved in and threw off the balance of the neighborhood. Tension grew between mothers divided by different notions of well-behaved children. Disputes over discipline spilled over into disparaging remarks about family budgets and personal habits. Some women ceased speaking 
to each other and those who did speak gossiped about their neighbors. Finally, one of the quarreling boys appealed to his adult brother rather than his mother for sympathy. This drew the men into the conflict. Neighborhood men threatened each other with insults and summonses. Two factions crystallized while other neighbors tried to keep to themselves. Finally, the Dodd and Beardmore men lodged a complaint at Bootle Police Station against their neighbor, Constable Rayner, in an attempt to silence a faction including Rayner's wife. A formerly supportive neighborhood had completely broken down. ${ }^{36}$

Unraveling the surviving statements and letters that this complaint produced suggests a picture of neighborhood wives originally getting along though sometimes upset by disagreements over children. Mrs. Beardmore stated that she had gotten along with Mrs. Rayner and that "The times when we haven't been exactly friendly have been when we have had disputes over the children." ${ }^{137}$ Mrs. King agreed; there had been "little quarrels over the children but never anything serious." ${ }^{38}$ But underlying these squabbles were small but important degrees of status; Russell Street was slightly nicer than Princess Road even though they shared an entry way. Princess Road was a busy throughway while Russell Street was quieter and closer to the park. Generally speaking, Russell Street inhabitants had lived there longer, and they tended to have better jobs with better prospects for promotion. These differences were minor but enough to create tension about family status and the real or claimed superiority of neighbors.

Local neighborliness began degenerating soon after the Dodd and Simpson families moved onto Princess Road, their arrival upsetting a careful harmony of acceptable street behavior. They had stricter notions of space than the older neighbors, and refused to talk to their neighbors if these boundaries were transgressed. When the Rayner daughter went to recover a ball that had fallen into the Dodd's yard without knocking at the gate, the Dodds were rude about giving it back. In particular, the Rayner daughter's fearless character upset the Dodds and Simpsons, although not the older neighbors who knew the girl. Mrs. Rayner was perceived by the Dodds and Simpsons as not controlling her daughter adequately. Like many families preferring privacy, the Dodds could be remarkably vocal in their complaints. This was resented by older residents, particularly on the slightly nicer Russell Street.

A minor quarrel between children set off tensions that had been building for months. The Dodd and Rayner boys hit each other and the Rayner girl hit Harry Dodd to protect her brother. Found crying by his adult brother Bertram, Harry said that he had been slapped by Mrs. Rayner rather than admit that he had been hit by a girl. Bertram took Harry around to the Rayner's back door. He described Constable Rayner's behavior as "very aggressive", including threatening to give Harry a "bloody good hiding." Bertram told Rayner that if he hit Harry, he would summons him for assault. At this, Rayner "became very abusive, shouted at me, and called me 'a shortarsed sod."' Bertram could hear Rayner shouting at him for some time after this, enough to draw neighbors out of their houses to listen. ${ }^{39}$ Mr. Lenehan, a longtime resident of Russell Street, gave quite a different version of events. He saw Bertram come out of his yard and kick at the Rayner's gate. Mrs. Rayner came out and Bertram shook his fist and yelled at her. Lenehan was on the point of coming to Mrs. Rayner's defense when Constable Rayner came to the door. Bertram said, "I am not afraid of a dozen like him" and threatened 
to summons Mrs. Rayner. Mr. Rayner replied, "Well, you have as much right to get a summons as anyone else." $\mathrm{Mr}$. Rayner then went in and bolted the door. Lenehan concluded, "I am a law abiding man but if any man has spoken to my wife or threatened her as Dodds did to Mrs. Rayner, I would have taken the law into my own hands. ${ }^{20}$ Rayner most likely had spoken in a threatening manner to Bertram, but clearly Lenehan believed that Rayner was justified in being angry at Bertram for threatening his wife.

The quarrel became a contest between the men, asserting their dominance. Bertram saw himself as protecting his brother while Lenehan supported Rayner for defending his wife against Bertram's violence. Rayner was heard to declare, "I'll show them, I'm cock of this bloody entry." 41 Bertram's violent confrontation with the Rayners became a threat to the neighborhood hierarchy and Rayner was reminding him in no uncertain terms who was boss. Husbands threatened each other in defense of their wives. After Mrs. Beardmore spread vicious and inaccurate gossip against Mrs. Rayner for hitting the boy, Constable Rayner yelled at Mr. Beardmore for not controlling his wife. Mr. Beardmore rebuked Rayner, saying, "You, being a Policeman, should have more sense than have rows with people over children, you are supposed to keep order." $" 42 \mathrm{He}$ told the Rayners that he would report Rayner to "Headquarters," escalating the crisis still further.

More neighbors became involved and the original children's quarrel was forgotten in malicious gossip and arguments over respectability. Neighbors tended to side more with their own street regardless of how long they had lived in the neighborhood, underscoring that status seemed to be the source of most of the tension. ${ }^{43}$ Mrs. Beardmore, a Princess Road resident who had lived comfortably with her neighbors for years, suddenly emerged as the most vindictive antagonist of Mrs. Rayner. Perhaps she had only tolerated the old neighborhood standards previously and the newly arrived Dodds and Simpsons finally gave her allies to impose her will on her Russell Street neighbors. Soon after the run-in of the husbands, Mrs. Beardmore went up to Mrs. Rayner and said, "What's the idea of picking on my husband, what has he done to you, didn't you cause enough trouble last night." Mrs. Rayner, angered by her malicious talk in neighborhood kitchens, replied by calling her a "two-faced bugger," a "dirty bloody prostitute" and a "dirty bloody bitch."44 These two women had lived calmly on the same street for five years, yet after a year of growing friction, the two women hurled insults at each other. Mrs. Rayner finally had had enough of Mrs. Beardmore's gossip and Mrs. Beardmore had had enough of Mrs. Rayner's superior airs.

The neighborhood dispute came to the attention of the Manchester Police when Bertram Dodd and Charles Beardmore complained about Rayner's conduct. While the men made the complaint to stop Constable Rayner's insulting behavior, the goal of the wives was not so much to punish Mr. Rayner as it was to attack his wife in a campaign to upset the old standards in favor of the new. When a police sergeant took statements, the men gave careful and abbreviated accounts of the altercations that had led to the complaint. The women, however, were much more forthcoming, including detailed descriptions and uncomplimentary comments about themselves made by other women. While Mrs. Dodd, Mrs. Beardmore and others agreed that they wanted Mr. Rayner to control his wife, it was clear from their own testimony that few of the husbands had 
much control over their wives' behavior. The Princess Road wives took advantage of a fight between Mr. Rayner and their men to silence Mrs. Rayner and the rest of Russell Street. Even though Mr. Rayner was not disciplined, his Princess Road neighbors got their way in his family leaving the area. How the neighbors lived with each other after this crisis is open to question since even without the Rayners, factions seemed evenly divided. In the end, the vehemence of the wives may have defeated the purpose of the original complaint, breaking up the neighborhood rather than simply quieting or getting rid of Mrs. Rayner.

Despite the many examples from police records of neighbors clashing with each other, the pattern of supportive neighborhoods found by other historians had not vanished. Even the conflicts illustrated how generally amicable streets dealt with one or two troublesome families; huge battles were fairly unusual. Neighbors helped each other to protect and keep compatible neighbors, not just to change or move people. One such case made it into police records unintentionally after neighbors tried to stop a domestic assault out of concern for the family rather than out of anger at the man. Constable Wilkinson had lived on Elsie Street for many years and was well liked except for a drinking problem. Coming home drunk one night after a sports event, Wilkinson attracted the attention of two Hulme families when he broke a pane of glass, shouted at his wife, and grabbed her by the hair. The Hulmes ran towards his house to stop him. ${ }^{45}$ Wilkinson shouted out the window that "I will show the bloody lot of you what I can do," ran into the street and challenged the men to fight. Both Hulme men advised Wilkinson to go home and sleep it off. Unfortunately for Wilkinson, two other police families lived on the block. The wife of Constable Davenport heard the ruckus and Constables Davenport and Hawley arrived on the scene. They managed to get Wilkinson back into his house in spite of his struggles against them. Concerned about his drinking, they reported him to the local station. When an inspector showed up, Wilkinson had passed out and his wife was "greatly distressed." The next day, Wilkinson could not remember anything and apologized profusely to his wife, the constables, and his neighbors. Wilkinson remained on the block but was ordered to keep his drinking under control. Here, neighbors had tried to defuse a nasty situation, protecting Mrs. Wilkinson, without getting her husband into trouble. In none of the interviews was there any hint of animosity towards him, even by the two constables, but rather concern for his welfare and hope that his drinking problem could be resolved. ${ }^{46}$

Finding good neighbors could make all the difference between a comfortable life and upheaval, but this became more difficult after the First World War with more families on the move. Working-class families tried to find areas with similar standards regarding noise, space and privacy. As like-minded families clustered together, one street could vary significantly in character from the next. Neighborhoods evolved, creating stress if changes occurred too quickly or too dramatically. Even minor tensions could unsettle streets since causes of strain tended to reflect on respectability and status. The increasing presence of men in family life exacerbated misunderstandings, adding frictions over masculinity and territoriality. When differences became too extreme, neighbors did not suffer in silence, but started campaigns of arguments, complaints, and harassment. Ultimately, if one or two families were not in harmony with the rest of 
a street, efforts might be made to force them to move. Policemen were particularly susceptible to this pressure since police forces could not afford to have their men in conflict with their neighbors. Few cases were simple. Complaints over noise overlapped with concerns over space which overlapped with anxiety over respectability and masculinity, all aggravated by children and gossip. Yet despite the lament of the Manchester Chief Constable that it was "a pity that neighbours cannot live in amiry with each other" ${ }^{\prime \prime}$, neighborliness had not disappeared. Working-class neighbors generally managed to get along with each other without much commotion even in the unsettled conditions of interwar Liverpool and Manchester.

Department of History

Boise, ID 83725

\section{ENDNOTES}

1. See Ellen Ross, "Survival Networks: Women's Neighbourhood Sharing In London Before World War I," History Workshop, 15 (Spring 1983): 4-27; Elizabeth Roberts, A Woman's Place: An Oral History of Working Class Women 1890-1940, (Oxford, 1984, 1996); Ellen Ross, "'Not the Sort that Would Sit on the Doorstep': Respectability in Pre-World War I London Neighborhoods," Intemational Labor and Working Class History, 27 (Spring 1985): 39-59; Melanie Tebbutt, Women's Talk?: A Social History of 'Gossip' in Working-class Neighbourhoods, 1880-1960 (Aldershot, 1997).

2. See Andrew Davies, Leisure, Gender, and Poverty: Working-class Culture in Salford and Manchester, 1900-1939 (Buckingham, 1992). See also Stephen Humphries, Hooligans or Rebels?: An Oral History of Working-class Childhood and Youth, 1889-1939 (New York, 1984).

3. See Catherine Hall, "Married Women at Home in the 1920s and 1930s," Oral History, 5 (no. 2, 1977): 76; Joanna Bourke, Working-class Cultures in Britain 1890-1960: Gender, Class and Ethnicity (London, 1994), 64, 82-88.

4. Liverpool City Police Chief Constable's Disciplinary Reports (LCCDR), 3 June 1932, PCH 137 Jones, complainant Mr. Woods, 1 Balcarres Ave., Sefton Park.

5. Ross (1983).

6. See Bourke, pp. $88-89$, for men's growing involvement in gardens and allotments after the First World War.

7. Only one reference to a neighbor informing a civilian employer to get another neighbor into trouble was found in police records. William McGuiness and his wife "were of superior type and excellent address" which aggravated PC Parry and his wife. They began "continually annoying" the McGuinesses. McGuiness charged that Mrs. Parry had written to McGuiness' employers to get him into trouble. (LCCDR, 9 May 1935, PCG 242 Parry, complainant William McGuiness, 400 East Prescot Rd, Parry warned as to his future conduct.)

8. Manchester City Police General Orders (MGO), 9 May 1931.

9. MGO, 9 May 1931. 
10. LCCDR, 24 April 1929, PSA 49 McLellan, complainant R.G. Todd, 35 Sedgewood Road, Norris Green.

11. See Bourke (1994), Rosemary Crook, "'Tidy Women': Women in the Rhondda Between the Wars," Oral History Journal, 10 (no. 2, 1982): 40-46., E. Roberts (1984), Ross $(1983,1984)$, and Tebbutt (1997) for detailed descriptions of the effort involved in keeping up appearances.

12. LCCDR, 28 May 1931, PCE 129 Pirie, complainant John Dutch, 109 Chatsworth Ave., Orrel Park. Pirie was advised to keep on good terms with his neighbors.

13. LCCDR, 23 December 1937, PCD 57 Young, complainant J.P. Scott, 145 Townsend Ave., matter was dropped when Scott moved. In a conflict over front yards, Mrs. Mudie allowed her dog to urinate on the Mackay's gate post every day. Constable Mackay complained to her, leading to an argument between the two husbands. The Mudies complained successfully since Mackay was warned that he would have to move if further complaints occurred. (LCCDR, 23 August 1937, PCA 163 Mackay, complainant Edgar L. Mudie, 31 Warnerville Road, no charge framed.)

14. Constable Dowler jumped over his fence to beat up his neighbor for using insulting language towards his wife. Mrs. Dowler helped to hold Mr. Calvert down while her husband hit him. The chief constable advised Calvert to summons the Dowlers for assault but he declined for unknown reasons. (LCCDR, 10 December 1932, PCE 121 Dowler, complainant Wilfred Calvert, 11 Bramhill Rd., West Derby, no charge framed.)

15. Ross (1983), 12; Carl Chinn, They Worked All Their Lives: Women of the Urban Poor in England, 1880-1939 (Manchester, 1988), 43.

16. LCCDR, 14 April 1934, PCA 243 Baker, complainant Mrs. Louise R. Lord, 5 Aconbury Place.

17. Bourke, 90 .

18. LCCDR, 2 October 1934, PCG 130 Corlett, complainant W.L. Beeney, 1 Bramhill Rd., West Derby; no action taken; 2 November 1937, PCA 310 Tinsley, complainant John Ferguson, at 12 Wilberforce Rd, no charge framed. Tinsley was forced to apologize to his neighbor by his chief superintendent. It is unknown whether or not the daughter was punished.

19. LCCDR, 1 June, 3 September 1937, PCG 94 Williams, complainant Mr. House, 8 Agar Road, West Derby. The Kellys and the Raithbys had a long history of hurling insults at each other. One day, Joseph Kelly cut a hedge dividing their yards and the Raithby son told him that "he was making a - mess." Kelly complained to the Liverpool chief constable and Raithby was advised to move. (LCCDR, 15 June 1935, PSE 29 Raithby, complainant Joseph Kelly, 595 Queens Drive, Stoneycroft)

20. LCCDR, 18 June 1936, PCA 93 Pritchard, complainant Mr. Grundy, 23 Clinton Place, West Derby.

21. LCCDR, 7 January 1931, PCH 278 Boss, complainant George F. Jackson, 28 Corona Rd., Old Swan. "Div Supt. said complaint was frivolous. CC 6.1.31. I am not disposed to take action."

22. LCCDR, 27 June 1936, PSA 5 Charnley, complainant R.H. Lambert, 558 Mather Ave. No charge framed. Charnley stated that "His own family are in bed \& no unnecessary noise has been made." 
23. LCCDR, PCG 199 Mutch ( $\&$ his wife), complainant F. Peck, 89 Queens Drive, West Derby, no charge framed.

24. Davies, pp. 42-43.

25. LCCDR, PCH 219 Turner, complainants J.W. Hughes and R. Bruce, 10 Flaxman St. Turner denied knowing the men but cautioned for writing the letters. No charge framed.

26. LCCDR, PCH 64 Casson, complainant Waller Wright, 23 Berwyn Rd., L-pool. "A little tolerance appears to be needed on both sides. No charge framed."

27. Manchester City Police Personnel Files (MPF), 24, 26, 30 January, 24 March, 1, 2 April 1937, PCF 91 James Higgins, appointed May 1937; events took place while he was in his probationary year.

28. LCCDR, PCG 183 Walley, complainant George Abbott, 6 Ashcombe Rd, L-pool, regarding offense taken at abusive language, no charge framed.

29. MPE, 6, 7 November 1927, PCB 38 Albert Wright, appointed April 1914, retired 1940.

30. Today, police officers will often ignore complaints about noise called in around midnight on New Years Eve or after dark on July Fourth, considering such complaints to be unreasonable. My thanks to officers who shared this observation with me.

31. MPF, Wright.

32. MPF, 30 January, 6, 12, 13 February 1935, PCB 82 Albert Victor Bradford Entwistle, appointed August 1920.

33. Pat Ayers and Jan Lambertz, "Marriage Relations, Money, and Domestic Violence in Working-Class Liverpool, 1919-1939," in Labour and Love: Women's Experience of Home and Family 1850-1940, ed. Jane Lewis (Oxford, 1986), 194-197.

34. MPF, 10, 13, 14, 16 August 1932, PCA 50 Fred Carlis, appointed September 1922. The couple apparently separated. He eventually retired from the police so these events did not lose him his job.

35. MPF, 31 May, 3,5, June, 4 September 1935, PCA 126 Richard Stonehouse Thompson, appointed April 1926.

36. MPF, 18, 22, 23, 24, 26, 27 June, 3 July 1938, PCA 211 James William Rayner, appointed September 1923.

37. MPF, Rayner, statement of Dorothy Beardmore, wife of Charles Beardmore, 228 Princess Road, Moss Side, Manchester, 23 June 1938.

38. MPF, Rayner, statement of Elizabeth King, wife of Christopher King, 131 Russell Street, Moss Side, Manchester, 22 June 1938.

39. MPF, Rayner, interview of Bertram Dodd, 220 Princess Road, Moss Side, Manchester, taken 18 June 1938, at Bootle Police Station.

40. MPF, Rayner, letter of John Lenehan, 123 Russell St, to chief constable, 3 July 1938.

41. MPF, Rayner, interview of Bertram Dodd, 220 Princess Road, Moss Side, Manchester, taken 18 June 1938, at Bootle Police Station; see also statement of Ellen Simpson, widow, 222 Princess Road, Moss Side, Manchester, 23 June 1938. 
42. MPF, Rayner, interview of Charles Beardmore, 228 Princess Road, Moss Side, Manchester, taken 18 June 1938, at Bootle Police Station.

43. One Princess Road family spoke in support of the Rayners but their statements are missing from the file. Four neighborhood families and three from elsewhere supported the Rayners but only two statements remain in his file. Four Princess Road families spoke against the Rayners and their statements survive. One statement did not support either family.

44. MPF, Rayner, statement of Dorothy Beardmore, wife of Charles Beardmore, 228 Princess Road, Moss Side, Manchester, 23 June 1938.

45. E. Roberts found that neighbors would physically restrain men abusing their wives or children.(E. Roberts, p. 194)

46. MPF, 19 July 1923, PCB 130 William Wilkinson, appointed January 1920, reduced to lowest class and transferred for being "mad with drink" and striking a constable.

47. MPF, Entwistle. 